\title{
A Multi-Objective Decision Making Approach For Mutual Fund Portfolio
}

Hari P.Sharma,(E-mail: haripsharma@yahoo.com), Virginia State University

Dinesh K. Sharma, (E-mail: dksharma@mail.umes.edu), University of Maryland Eastern Shore

\begin{abstract}
Investment decision-making problems are generally multi-objective in nature such as minimization of the risk and maximization of the return. These problems can be solved efficiently and effectively using multi-objective decision making (MODM) tools such as a lexicographic goal programming (LGP). This paper applies the LGP model for selecting an optimum mutual fund portfolio for an investor, while taking into account specific parameters including risk, return, expense ratio and others. Using sensitivity analysis on the weights in a priority structure of the goals identifies all possible solutions in the decision-making process. The Euclidean distance method is then used, to measure distances of all possible solutions from the identified ideal solution. The optimum possible solution is determined by the minimum distance between the ideal solution and other possible solutions of the problem. The associated weights will be the most appropriate weights in a given priority structure. The effectiveness and applicability of the LGP model is demonstrated via a case example from broad categories of mutual funds.
\end{abstract}

\section{INTRODUCTION}

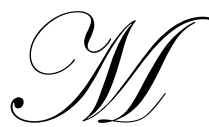

odern portfolio theory is based on the pioneering works of Markowitz $(1952,1959)$ and Sharpe (1963). In 1952, Markowitz first laid the foundation of a framework for mean-variance portfolio optimization. He suggested that the portfolio selection problem should be considered as a parametric quadratic programming approach. Several portfolio selection models were previously proposed based on meanvariance formulation. However, the complexity of the models requires training in quadratic programming and its practical application presents a number of problems. First, a large amount of data must be processed, which of course requires performing significant computation. Second, the results are given in the form of alternative optimal portfolios, which require further determination of the best choice. Finally, the size of the optimal portfolio leads to the concept of un-diversifiable market risk, since more securities are held in the portfolio. Sharpe (1963) developed a revised model and summarized the process of portfolio selection based on the assumptions of: (1) making probabilistic estimates of the future performance of securities, (2) analyzing those estimates to determine an efficient set of portfolios, and (3) selecting from that set the portfolio best suited to the investor's performance requirements (Lee and Lerro, 1973).

Sharpe $(1967,1971)$ and Stone (1973) used linear programming (LP) approach to solving portfolio selection problems and demonstrated that LP models for portfolio selection can provide acceptable results while avoiding the limitations of mean-variance models (Levary and Avery, 1984). Portfolio selection problems typically involve multiple and often conflicting objectives such as the maximization of returns and minimization of risk. As a result of multiple and conflicting objectives, the conventional LP model becomes less adequate to handle mutual fund portfolio selection problems as it was developed to handle a single objective function. However, the complexity of the problems resulting from multiple and conflicting objectives can be handled efficiently and effectively with a multi-objective decision making (MODM) techniques such as a lexicographic goal programming (LGP). For a detailed research survey on LGP, see Lee (1972), Ignizio (1976), Romero (1986, 1991), Tamiz and Jones (1995), Sharma, Alade and Vasishta (1999), and Steuer and $\mathrm{Na}$ (2003). 
Over the years, LGP has been widely used to solve problems in investment decision-making (Pendaraki et. al., 2004). However, there are a few studies that have applied LGP to construct a portfolio from broad categories of mutual funds. Most studies have used conventional LGP to provide the optimal solution and included only a few goals and objectives under the decision-maker's priority structure. In this study we have included additional objectives and constraints to make it a more practical decision-making technique that provides a better solution that may be widely acceptable in a defined priority structure. A better solution also requires a sensitivity analysis on different weights within a given priority structure (Steuer, 1986 and Sharma et al., 2004).

The purpose of this paper is to apply the LGP model, in line with previous studies, to construct an optimum mutual fund portfolio for an investor, taking into account specific parameters including risk, return, expense ratio and others. The model can meet the requirements of an individual investor and/or practitioners effectively and efficiently and satisfies a wide spectrum of goals and objectives. We perform sensitivity analysis on the weights in a given priority structure of the goals to find all possible solutions in the decision-making process. We then use the Euclidean distance method to measure distances of all possible solutions from the identified ideal solution. The optimal possible solution is determined based on the minimum distance between the ideal solution and other possible solutions of the problem. The associated weights will be the most appropriate weights in the given priority structure. The effectiveness and applicability of the LGP model is demonstrated via a case example from broad categories of mutual funds.

The remainder of the paper is organized as follows: The second section discusses the review of literature. The third section proposes the mathematical model of the problem. The fourth section demonstrates the model via a case example and presents sensitivity analysis with different weight structures in a priority structure. The fifth section analyses the result obtained from the case example and identifies the most acceptable solution in the decision-making process. The final section presents concluding remarks.

\section{Review of Literature}

Over the years, multiple criteria decision making (MCDM) has attracted many researchers because of its theoretical development and practical applications for solving a wide range of real world problems in business and industry (Hwang and Masud, 1979; Steuer, 1986). The MCDM is concerned with the methods and procedures by which multiple criteria can be formulated into the analytical process. This process can be divided into multi-attribute decision making (MADM) and multi-objective decision making (MODM). The former is often applicable to problems with a small number of alternatives in a probabilistic environment, while the later is generally applied to deterministic problems where the number of feasible alternatives is large. Lexicographic goal programming (LGP) falls in the category of MODM that is broad in scope (Messac, Gupta, and Akbulut, 1996). LGP is one of the most widely used tools for solving MODM problems (Romero, 1991).

GP and its variants have been applied to a wide range of problems (Ijiri 1965, Ignizio 1976, Lee 1972, Romero 1991). Literature is replete with studies using LGP or linear GP for investment decision-making problems (Lee, 1972; Lee and Lerro, 1973; Kumar et al., 1978; Lee and Chesser, 1980; Levary and Avery (1984), Schniederjans et al., 1992; Sharma et al., 1995; Cooper et al., 1997; Dominiak, 1997; Leung et al., 2001; Pendaraki et. al., 2004). Lee and Lerro (1973) developed a LGP portfolio selection model for mutual funds. Kumar et al. (1978) developed a conceptual LGP model for portfolio selection of dual-purpose funds. Lee and Chesser (1980) demonstrated how linear beta coefficient from finance theory reflecting risk in alternative investments could be incorporated into a LGP model. Levary and Avery (1984) also introduced a LGP model representing the investor's priorities and also compared the use of linear programming to GP for the selection of optimal portfolio. Schniederjans et al. (1992) illustrated the use of LGP as an aid to investors planning investment portfolios for themselves. Sharma et al. (1995) presented LGP as an aid for investors or financial planners planning investment portfolios for individuals and/or companies by using beta coefficients and other important parameters. Recently, Pendaraki et al., 2004 has applied LGP on a sample of Greek mutual funds.

\section{Goal Programming Model Development}

Goal programming (GP) technique was initially developed to handle multi-criteria situations within the general framework of LP. The essence of the technique is the achievement of the "best possible" solution, which 
comes closest to meeting the stated goals given the constraints of the problem. GP was first introduced by Charnes et al. (1955) and Charnes and Cooper (1961). It was later extended by Ijiri (1965), Lee (1972), and Ignizio (1976). The GP model has been described in detail by Lee (1972), Ignizio (1976), Romero (1991), and others. LGP is useful in financial planning because many of financial criteria can be expressed in terms of goals. A general format for a LGP model is Minimize $\left[P_{1}(\bar{d}), \ldots . ., P_{k}(\bar{d}), \ldots \ldots, P_{K}(\bar{d})\right]$,

subject to,

$$
\begin{aligned}
& \mathrm{f}_{\mathrm{i}}(\mathrm{x})+\mathrm{d}_{\mathrm{i}}^{-}-\mathrm{d}_{\mathrm{i}}^{+}=\mathrm{b}_{\mathrm{i}}, \mathrm{i}=1,2, \ldots, \mathrm{m} \\
& \mathrm{d}_{\mathrm{i}}^{-}, \mathrm{d}_{\mathrm{i}}^{+}, \overline{\mathrm{x}} \geq 0 \text { and } \mathrm{d}_{\mathrm{i}}^{-} \cdot \mathrm{d}_{\mathrm{i}}^{+}=0 .
\end{aligned}
$$

Where $\mathrm{P}_{\mathrm{k}}(\mathrm{d})=\mathrm{P}_{\mathrm{k}}\left(\mathrm{w}_{\mathrm{ik}}^{-} \mathrm{d}_{\mathrm{ik}}^{-}+\mathrm{w}_{\mathrm{ik}}{ }^{+} \mathrm{d}_{\mathrm{ik}}{ }^{+}\right)$and $\mathrm{P}_{\mathrm{k}}$ is the $\mathrm{k}$-th priority structure. $w_{i k}^{-}$and $w_{i k}^{+}$are the numerical weights associated with the deviational variables $d_{i k}^{-}$and $d_{i k}^{+}$respectively at the priority level $P_{k} . \bar{x}$ is the vector of decision variables. $\mathrm{f}_{\mathrm{i}}($.$) is the \mathrm{i}$-th goal constraint.

The model approaches the problem of determining the optimum portfolio under a set of goals and constraints imposed by the decision-maker. This is achieved by minimizing a weighted sum of deviations from the target goals. In order to develop a multi-objective goal function, each goal has to be assigned its due weight from decision-maker's point of view.

\section{THE GOALS}

The decision-maker's multiple goals are defined as follows:

1. Utilize total available funds for investment within imposed restrictions.

2. Maximize the portfolio's expected annual return.

3. Minimize the portfolio's risk (Beta and Standard Deviation).

4. Minimize the portfolio's expense ratio.

These target goals may vary from investor to investor, depending on the adjustment of the model to fit different economic environments.

\section{Goal Constraints}

The following goal constraints are developed in formulating the general model of mutual fund portfolio selection problem.

\section{Investment}

The objective of decision maker is to utilize the total available funds (F). The available funds goal constraint by adding under and over-deviations can be written as:

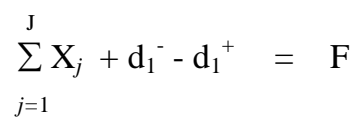

where $\mathrm{X}_{j}$ is the amount of money allocated to mutual fund $j(=1,2, \ldots, \mathrm{J}), \mathrm{d}_{1}{ }^{-}$and $\mathrm{d}_{1}{ }^{+}$are underachievement and overachievement of goal constraint in the equation.

Rate of Return: The decision maker's objective is to get the maximum possible return on the investment. The total annual return (A) goal constraint can be expressed as:

J

$\sum \mathrm{A}_{j} \mathrm{X}_{j}+\mathrm{d}_{2}{ }^{-}-\mathrm{d}_{2}{ }^{+}=\mathrm{A}$ 


$$
j=1
$$

where $\mathrm{A}_{j}$ is the expected annual rate of return from mutual fund $j(=1,2, \ldots, \mathrm{J})$.

Risk Willingness: (a) Beta: The portfolio's beta $(\beta)$ is called systematic risk and is measured as the sensitivity of a security's returns to market returns. The composite $\beta$ of the portfolio can be presented as:

$$
\sum_{j=1}^{\mathrm{J}} \beta_{j} \mathrm{X}_{j}+\mathrm{d}_{3}^{-}-\mathrm{d}_{3}^{+}=\beta_{a} \mathrm{~F}
$$

where $\beta_{\mathrm{j}}$ is the measure of risk associated with mutual fund $j(=1,2, \ldots, \mathrm{J})$ and $\beta_{a}$ is an acceptable level of beta.

(b) Standard Deviation: Theoretically, a well-diversified portfolio's standard deviation is reflected in its systematic risk. However, the existence of some residual or nonsystematic risk is also possible due to fund specific performance. The composite standard deviation $(\sigma)$ of the portfolio may be limited to a certain maximum value and thereby limiting risk to a certain level. The goal constraint can be expressed as:

$$
\sum_{j=1}^{\mathrm{J}} \sigma_{j} \mathrm{X}_{j}+\mathrm{d}_{4}^{-}-\mathrm{d}_{4}^{+}=\sigma_{a} \mathrm{~F}
$$

where $\sigma_{\mathrm{j}}$ is the measure of nonsystematic risk associated with mutual fund $j(=1,2, \ldots, \mathrm{J})$ and $\sigma_{a}$ is an acceptable level of standard deviation.

Diversification: The modern portfolio theory suggests that the allocation of the investor's capital among various securities can reduce diversifiable risk or nonsystematic risk. In order to reduce risk through diversification, the decision maker may prefer to invest some minimum amount in several different mutual funds, but at the same time establish a maximum amount that can be invested in any particular mutual fund. The diversification goal constraints can be written as:

(a) Large Cap Mutual Funds: The large cap mutual funds $\left(\mathrm{X}_{l}\right)$ should be at least a certain percentage (p) of total mutual fund. The goal constraint would be written as:

$$
\sum_{l=l_{1}}^{l_{n}} \mathrm{X}_{l \in\{1,2, \ldots, \mathrm{J}\}}+\mathrm{d}_{5}{ }^{-}-\mathrm{d}_{5}^{+}=\mathrm{p} \% * \mathrm{~F}
$$

where $\left\{1_{1}, 1_{2}, \ldots, 1_{n}\right\}$ are the large cap mutual funds and $\left\{1_{1}, 1_{2}, \ldots, 1_{n}\right\} \subseteq\{1,2, \ldots, J\}$.

(b) Medium Cap Mutual Funds: The medium cap mutual funds $\left(\mathrm{X}_{m}\right)$ may not exceed a certain percentage (q) of total mutual funds. The goal constraint can be expressed as:

$$
\sum_{m=m_{1}}^{m_{n}} \mathrm{X}_{\mathrm{m} \in\{1,2, \ldots \mathrm{J}\}}+\mathrm{d}_{6}^{-}-\mathrm{d}_{6}^{+}=\mathrm{q} \% * \sum_{j=1}^{J} \mathrm{X}_{j}
$$

where $\left\{\mathrm{m}_{1}, \mathrm{~m}_{2}, \ldots, \mathrm{m}_{\mathrm{n}}\right\}$ are the medium cap mutual funds and $\left\{\mathrm{m}_{1}, \mathrm{~m}_{2}, \ldots, \mathrm{m}_{\mathrm{n}}\right\} \subseteq\{1,2, \ldots, \mathrm{J}\}$

(c) Small Cap Mutual Funds: The small cap mutual funds $\left(\mathrm{X}_{\mathrm{s}}\right)$ must be at least a certain percentage (r) of total mutual fund. The goal constraint can be defined as:

$$
\sum_{s=s_{1}}^{s_{n}} \mathrm{X}_{\mathrm{s} \in\{1,2, \ldots \mathrm{J}\}}+\mathrm{d}_{7}^{-}-\mathrm{d}_{7}^{+}=\mathrm{r} \% * \sum_{j=1}^{J} \mathrm{X}_{j}
$$

where $\left\{\mathrm{s}_{1}, \mathrm{~s}_{2}, \ldots, \mathrm{s}_{\mathrm{n}}\right\}$ are the small cap mutual funds and $\left\{\mathrm{s}_{1}, \mathrm{~s}_{2}, \ldots, \mathrm{s}_{\mathrm{n}}\right\} \subseteq\{1,2, \ldots, \mathrm{J}\}$

(d) Foreign Mutual Funds: The foreign mutual funds $\left(\mathrm{X}_{\mathrm{f}}\right)$ may not exceed a certain percentage (s) of total mutual fund. The goal constraint can be written as:

$$
\sum_{f=f_{1}}^{f_{n}} \mathrm{X}_{\mathrm{f} \in\{1,2, \ldots \mathrm{J}\}}+\mathrm{d}_{8}{ }^{-}-\mathrm{d}_{8}{ }^{+}=\mathrm{s} \% * \sum_{j=1}^{J} \mathrm{X}_{j}
$$


where $\left\{\mathrm{f}_{1}, \mathrm{f}_{2}, \ldots, \mathrm{f}_{\mathrm{n}}\right\}$ are the foreign mutual funds and $\left\{\mathrm{f}_{1}, \mathrm{f}_{2}, \ldots, \mathrm{f}_{\mathrm{n}}\right\} \subseteq\{1,2, \ldots, \mathrm{J}\}$

(e) Bond Mutual Funds: The bond mutual funds $\left(\mathrm{X}_{\mathrm{b}}\right)$ must be at least a certain percentage (t) of total mutual fund. The goal constraint can be written as:

$$
\sum_{b=b_{1}}^{b_{n}} \mathrm{X}_{\mathrm{b} \in\{1,2, \ldots \mathrm{J}\}}+\mathrm{d}_{9}{ }^{-}-\mathrm{d}_{9}{ }^{+}=\mathrm{t} \% * \sum_{j=1}^{J} \mathrm{X}_{j}
$$

where $\left\{b_{1}, b_{2}, \ldots, b_{n}\right\}$ are the bond mutual funds and $\left\{b_{1}, b_{2}, \ldots, b_{n}\right\} \subseteq\{1,2, \ldots, J\}$

Similarly, other restrictions for each type of fund may also be considered.

Minimum and Maximum Limits on Investment: (a) Minimum Investment: Generally, each mutual fund company requires a minimum initial investment $(\mathrm{M})$ in each mutual fund. The goal constraint for minimum initial investment can be written as:

$\mathrm{X}_{j}+\mathrm{d}_{10}{ }^{-}-\mathrm{d}_{10}{ }^{+}=\mathrm{M}_{j, j}=1,2, \ldots, \mathrm{J}$

(b) Maximum Investment: Additionally, no more than a certain percentage (y) of the fund should be invested in a single mutual fund. The goal constraint for maximum investment in a fund can be defined as:

$\mathrm{X}_{j}+\mathrm{d}_{11}{ }^{-}-\mathrm{d}_{11}{ }^{+}=\mathrm{y} \% * \mathrm{~F}, j=1,2, \ldots, \mathrm{J}$

Annual Expense Ratio: Each mutual fund has an annual expense ratio. The expense ratio (E) goal constraint can be expressed as:

$$
\sum_{j=1}^{\mathrm{J}} \mathrm{E}_{j} \mathrm{X}_{j}+\mathrm{d}_{12}{ }^{-}-\mathrm{d}_{12}{ }^{+}=\mathrm{E}_{a} * \mathrm{~F}
$$

where $\mathrm{E}_{a}$ is acceptable level of expense ratio.

\section{Sensitivity Analysis}

The decision-maker defines priorities and weights to obtain optimal solution in the conventional LGP. However, in complex decision-making processes, the desired solution may not be acceptable under the imposed weights within a given priority structure. A better solution can be achieved by performing sensitivity analysis in which a number of different weight structures are allowed within a given priority structure (Steuer, 1986 and Sharma et al., 2004).

To determine the appropriate weight structure within the decision-maker's defined priority structure, we have used $\mathrm{K}$ priorities in constructing the model. Within a structure of $\mathrm{K}$ priorities, the decision-maker may impose $\mathrm{N}$ weight structures which are relevant to the study region. Therefore, $\mathrm{N}$ different solutions can be obtained from the problem with $\mathrm{N}$ sets of different weight structures.

Let $\mathrm{N}$ number of weight structures used to take different sets of solution of the model. $\mathrm{N}$ different sets of solution are:

$\left\{[X]_{j}^{n}\right\}, j=1,2,3, \ldots, J$ for each $n=1,2,3, \ldots, N$

Since in reality, maximum allocation of fund to a particular mutual fund is always desirable for getting maximum return. Thus the ideal solution can be identified as

$[X]_{j}^{*}, j=1,2,3, \ldots, J=$ Maximum $\left\{[X]_{j}^{n}\right\}, n=1,2,3, \ldots, N$, for each $j(=1,2,3, \ldots, J)$.

The Euclidean distance $\left\{D_{n}\right\}, n=1,2,3, \ldots, N$, of each solution $\left\{[X]_{j}{ }^{n}\right\}, j=1,2,3, \ldots ., J$ from the ideal solution $\left\{[\mathrm{X}]_{\mathrm{j}}^{*}\right\}, \mathrm{j}=1,2,3, \ldots ., \mathrm{J}$ can be presented as

$D_{n}=\sqrt{ } \sum\left([X]_{j}^{*}-[X]_{j}^{n}\right)^{2}, n=1,2,3, \ldots, N$ 
In practice, the ideal solution may not be achieved (Cohon 1978). The solution closest to the ideal solution, will be the best possible solution and the associate weight structure in the priority structure will be the most appropriate weight structure in the decision-making context.

To illustrate the LGP model developed in the previous section, the following case example is considered to demonstrate the usefulness of the model.

\section{Case example}

Mutual fund portfolio refers to a collection of tradable securities such as stocks, bonds, and money market funds. Fund managers select the basket of securities so as to achieve a good rate of return with the least risk exposure possible. However, Investors' desire to select an efficient portfolio of mutual funds requires further education to diversify investment capital across a broad range of mutual funds. Consider an investor that has one million dollars to invest in mutual funds. The objective of investor is maximum possible return on his investment with the least risk exposure possible, and diversify fund among twenty-five no-load mutual funds. The relevant financial data for the problem is given in Table 1.

Table 1: Summary of Data

\begin{tabular}{|c|c|c|c|c|c|c|}
\hline Mutual Fund & $\begin{array}{l}\text { Fund } \\
\text { Type }\end{array}$ & $\begin{array}{c}\text { Annual } \\
\text { Return (\%) }\end{array}$ & $\begin{array}{c}\text { Expense } \\
\text { Ratio }(\%) \\
\end{array}$ & Beta & $\begin{array}{c}\text { Standard } \\
\text { Dev. }\end{array}$ & $\begin{array}{c}\text { Min. Initial } \\
\text { Investment (\$) }\end{array}$ \\
\hline $\mathrm{X}_{1}$ & Large & 13.6 & 1.4 & 0.96 & 0.15 & 1,000 \\
\hline $\mathrm{X}_{2}$ & Large & 19.7 & 1.7 & 1.29 & 0.24 & 1,000 \\
\hline $\mathrm{X}_{3}$ & Large & 18.4 & 1.5 & 1.51 & 0.27 & 1,000 \\
\hline $\mathrm{X}_{4}$ & Large & 14.0 & 0.9 & 0.88 & 0.18 & 1,000 \\
\hline $\mathrm{X}_{5}$ & Large & 9.0 & 1.1 & 1.01 & 0.20 & 10,000 \\
\hline $\mathrm{X}_{6}$ & Medium & 9.5 & 1.0 & 0.66 & 0.14 & 2,500 \\
\hline $\mathrm{X}_{7}$ & Medium & 34.9 & 1.8 & 1.32 & 0.26 & 1,000 \\
\hline $\mathrm{X}_{8}$ & Medium & 27.2 & 1.0 & 0.91 & 0.39 & 2,500 \\
\hline $\mathrm{X}_{9}$ & Medium & 25.2 & 1.4 & 1.05 & 0.21 & 2,500 \\
\hline $\mathrm{X}_{10}$ & Medium & 36.1 & 1.0 & 1.35 & 0.39 & 2,500 \\
\hline $\mathrm{X}_{11}$ & Small & 24.6 & 1.6 & 0.89 & 0.18 & 1,000 \\
\hline $\mathrm{X}_{12}$ & Small & 35.6 & 1.6 & 1.63 & 0.40 & 1,000 \\
\hline $\mathrm{X}_{13}$ & Small & 15.1 & 1.5 & 1.30 & 0.22 & 2,000 \\
\hline $\mathrm{X}_{14}$ & Small & 9.8 & 1.1 & 0.88 & 0.16 & 1,000 \\
\hline $\mathrm{X}_{15}$ & Small & 6.2 & 0.3 & 1.0 & 0.28 & 3,000 \\
\hline $\mathrm{X}_{16}$ & Foreign & 24.5 & 2.8 & 0.94 & 0.30 & 1,500 \\
\hline $\mathrm{X}_{17}$ & Foreign & 23.7 & 1.6 & 1.08 & 0.28 & 1,000 \\
\hline $\mathrm{X}_{18}$ & Foreign & 24.6 & 2.1 & 1.51 & 0.26 & 1,000 \\
\hline $\mathrm{X}_{19}$ & Foreign & 32.8 & 2.3 & 0.93 & 0.30 & 1,000 \\
\hline $\mathrm{X}_{20}$ & Foreign & 31.9 & 1.7 & 1.17 & 0.36 & 2,500 \\
\hline$X_{21}$ & Bond & 10.09 & 0.6 & 0.95 & 0.13 & 1,500 \\
\hline$X_{22}$ & Bond & 11.02 & 0.5 & 0.90 & 0.12 & 2,000 \\
\hline$X_{23}$ & Bond & 8.5 & 0.7 & 0.85 & 0.14 & 2,500 \\
\hline$X_{24}$ & Bond & 7.0 & 0.6 & 0.70 & 0.10 & 2,000 \\
\hline $\mathrm{X}_{25}$ & Bond & 9.0 & 0.8 & 0.90 & 0.11 & 2,000 \\
\hline
\end{tabular}

Using the data in Table 1, the LGP model constraints for the mutual fund portfolio problem are formulated as follows:

\section{Constraints}

(i) The goal constraint for total investment in various mutual funds can be written as: 25

$$
\sum \mathrm{X}_{j}+\mathrm{d}_{1}^{-}-\mathrm{d}_{1}^{+}=\$ 1,000,000
$$

The goal constraint for annual rate of return from the investment is given below: 


$$
\mathrm{j}_{\mathrm{j}=1} \quad \sum \mathrm{A}_{j} \mathrm{X}_{\mathrm{j}}+\mathrm{d}_{2}^{-}-\mathrm{d}_{2}^{+}=215,000
$$

(iii) The goal constraint for the portfolio's beta can be expressed as:

$$
{ }^{25} \Sigma \beta_{\mathrm{j}} \mathrm{X}_{j}+\mathrm{d}_{3}{ }^{-}-\mathrm{d}_{3}{ }^{+}=1150,000
$$

$\mathrm{j}=1$

(iv) The goal constraint for standard deviation is given below:

$$
\sum_{j=1}^{25} \sigma_{\mathrm{j}} \mathrm{X}_{j}+\mathrm{d}_{4}^{-}-\mathrm{d}_{4}^{+}=\quad 267,500
$$

(v) The lower limit for initial investment (M) in each mutual fund can be written as:

$$
\mathrm{X}_{\mathrm{j}}+\mathrm{d}_{\mathrm{j}+4}{ }^{-}-\mathrm{d}_{\mathrm{j}+4}{ }^{+}=\quad \mathrm{M}_{\mathrm{j}} \quad(\mathrm{j}=1,2, \ldots, 25)
$$

(vi) The upper limit for investment in each mutual fund can be expressed as:

$$
\begin{array}{lll}
\mathrm{X}_{\mathrm{j}}+\mathrm{d}_{\mathrm{j}+29}{ }^{-}-\mathrm{d}_{\mathrm{j}+29}{ }^{+}= & 80,000 & (\mathrm{j}=1, \ldots, 5) \\
\mathrm{X}_{\mathrm{j}}+\mathrm{d}_{\mathrm{j}+29^{-}-\mathrm{d}_{\mathrm{j}+29}{ }^{+}=}= & 100,000 & (\mathrm{j}=6, \ldots, 10) \\
\mathrm{X}_{\mathrm{j}}+\mathrm{d}_{\mathrm{j}+29}{ }^{-}-\mathrm{d}_{\mathrm{j}+29}{ }^{+}= & 70,000 & (\mathrm{j}=11, \ldots, 15) \\
\mathrm{X}_{\mathrm{j}}+\mathrm{d}_{\mathrm{j}+29}-\mathrm{d}_{\mathrm{j}+29}{ }^{+}= & 50,000 & (\mathrm{j}=16, \ldots, 20) \\
\mathrm{X}_{\mathrm{j}}+\mathrm{d}_{\mathrm{j}+29}-\mathrm{d}_{\mathrm{j}+29}{ }^{+}= & 50,000 & (\mathrm{j}=21, \ldots, 25)
\end{array}
$$

(vii) The Large-cap mutual funds must be at least $30 \%$ of total investment.

$$
\sum_{\mathrm{j}=1}^{5} \mathrm{X}_{\mathrm{j}}+\mathrm{d}_{55}{ }^{-}-\mathrm{d}_{55}{ }^{+}=300,000
$$

(viii) The Medium-cap mutual funds may not exceed $40 \%$ of total mutual funds.

$$
\sum_{\mathrm{j}=6}^{10} \mathrm{X}_{\mathrm{j}}+\mathrm{d}_{56}{ }^{-}-\mathrm{d}_{56}{ }^{+}=.40 \sum \mathrm{X}_{\mathrm{j}} \quad{ }_{\mathrm{j}=1}^{25}
$$

(ix) The Small-cap mutual funds must be at least $20 \%$ of total mutual funds.

$$
\sum_{\mathrm{j}=11}^{15} \mathrm{X}_{\mathrm{j}}+\mathrm{d}_{57}{ }^{-}-\mathrm{d}_{57}{ }^{+}=\quad .20 \sum_{\mathrm{j}=1}^{25} \mathrm{X}_{\mathrm{j}}
$$

(x) The Foreign mutual funds may not exceed $10 \%$ of total mutual funds.

$$
\sum_{\mathrm{j}=16}^{20} \mathrm{X}_{\mathrm{j}}+\mathrm{d}_{58}{ }^{-}-\mathrm{d}_{58}{ }^{+}=\quad .10 \sum_{\mathrm{j}=1}^{25} \mathrm{X}_{\mathrm{j}}
$$

(xi) The Bond mutual funds may not exceed $15 \%$ of total mutual funds.

$$
\sum_{\mathrm{j}=20}^{25} \mathrm{X}_{\mathrm{j}}+\mathrm{d}_{59}{ }^{-}-\mathrm{d}_{59}{ }^{+}=\quad .15 \sum_{\mathrm{j}=1}^{25} \mathrm{X}_{\mathrm{j}}
$$

(xii) The annual expense ratio may not exceed $1.5 \%$ of total investment.

$$
\sum_{j=1}^{25} \mathrm{E}_{j} \mathrm{X}_{j}+\mathrm{d}_{60}{ }^{-}-\mathrm{d}_{60}{ }^{+}=15,000
$$

\section{The Priority Structure}

The priority structure for the model can be established by assigning each goal to a priority level, thereby ranking the goals in order of importance to the decision-maker. When more than one goal seems to be equally important for the achievement of their goals levels then they may be included at the same priority level, where numerical weights represent the relative importance of the goals at the same priority level. In this study, four priority levels are addressed to include the goal constraints according to their importance of achievement in the model. The priority structure in order of decreasing priority ranking of the goals can be defined in Table 2 . 
Table 2: Priority Structure

\begin{tabular}{|c|c|c|}
\hline Priority & Description & Deviations \\
\hline$P_{1}$ & $\begin{array}{l}\text { Utilize available funds and satisfy } \\
\text { restrictions on Investment }\end{array}$ & $\begin{array}{l}w_{l}^{+} d_{l}^{+}+\mathrm{w}_{\mathrm{j}_{+4}} \mathrm{~d}_{\mathrm{j}+4}+\mathrm{w}^{+}{ }_{\mathrm{j}+29} \mathrm{~d}^{+}{ }_{\mathrm{j}+29}+\mathrm{w}_{55}^{-} \mathrm{d}_{55}^{-}+\mathrm{w}_{56}^{+} \mathrm{d}_{56}{ }^{+}+\mathrm{w}_{57}^{-} \mathrm{d}_{57}^{-}+ \\
\left.\mathrm{w}^{+}{ }_{58} \mathrm{~d}^{+}{ }_{58}+\mathrm{w}^{+}{ }_{59} \mathrm{~d}_{59}^{+}\right], \mathrm{j}=1, \ldots, 25\end{array}$ \\
\hline$P_{2}$ & $\begin{array}{l}\text { Maximize the portfolio's expected } \\
\text { annual return }\end{array}$ & Jo 50 . \\
\hline$P_{3}$ & $\begin{array}{l}\text { Minimize the portfolio's risk (Beta and } \\
\text { Standard Deviation) }\end{array}$ & $\mathrm{w}_{3}^{+} \mathrm{d}_{3}^{+}+\mathrm{w}_{4}^{+} \mathrm{d}_{4}^{+}$ \\
\hline$P_{4}$ & Minimize the portfolio's expense ratio & $\mathrm{w}_{60}^{+} \mathrm{d}_{60}^{+}$ \\
\hline
\end{tabular}

\section{RESULTS ANALYSIS}

In the problem, four priorities and six different weight structures were considered. A sensitivity analysis on the weights in the given priority structure of goals is performed to obtain all feasible solutions. Therefore, six feasible solutions can be achieved from the analysis. In Table 3, solutions corresponding to six Runs are displayed and the calculated minimum distance of each solution set from the ideal solution set is also presented. The minimum distance from the solutions to the ideal solution corresponds to Runs 3 and 5. These two Runs have equal distance of 143941. In this situation, any Run out of these two Runs with the corresponding weight structure would be the most appropriate to make the investment decision.

Table 3: Priorities and Corresponding Solution

\begin{tabular}{|c|c|c|c|c|c|c|c|}
\hline Run & Weight Structure & Result & & & & & Distance \\
\hline 1 & $\begin{array}{l}\mathrm{P}_{1}\left(\mathrm{w}_{1}^{+}=\mathrm{w}_{\mathrm{j}+4}^{-}=\mathrm{w}^{+}{ }_{\mathrm{j}+29=}=\right. \\
\mathrm{w}^{+}{ }_{27}=\mathrm{w}_{55}^{-}=\mathrm{w}_{56}^{+}=\mathrm{w}^{-} \\
\left.{ }_{57}=\mathrm{w}_{58}^{+}=\mathrm{w}^{+}{ }_{59}=1\right) \\
\mathrm{P}_{2}\left(\mathrm{w}_{2}^{-}=1\right) \\
\mathrm{P}_{3}\left(\mathrm{w}^{+}=\mathrm{w}_{4}^{+}=1\right) \\
\mathrm{P}_{4}\left(\mathrm{w}_{60}^{+}=1\right)\end{array}$ & $\begin{array}{l}X_{1}=80,000 \\
X_{2}=1,000 \\
X_{3}=80,000 \\
X_{4}=80,000 \\
X_{5}=59,000\end{array}$ & $\begin{array}{l}X_{6}=100,000 \\
X_{7}=100,000 \\
X_{8}=87,500 \\
X_{9}=2,500 \\
X_{10}=100,000\end{array}$ & $\begin{array}{l}X_{11}=70,000 \\
X_{12}=70,000 \\
X_{13}=2,000 \\
X_{14}=1,000 \\
X_{15}=57,000\end{array}$ & $\begin{array}{l}X_{16}=1,500 \\
X_{17}=50,000 \\
X_{18}=45,000 \\
X_{19}=1,000 \\
X_{20}=2,500\end{array}$ & $\begin{array}{l}X_{21}=1,500 \\
X_{22}=2,000 \\
X_{23}=2,500 \\
X_{24}=2,000 \\
X_{25}=2,000\end{array}$ & 146972.8 \\
\hline 2 & $\begin{array}{l}\mathrm{P}_{1}\left(\mathrm{w}_{1}^{+}=\mathrm{w}_{\mathrm{j}+4}^{-}=\mathrm{w}^{+}{ }_{\mathrm{j}+29}=\right. \\
\mathrm{w}_{27}^{+}=\mathrm{w}_{56}^{+}=\mathrm{w}_{58}^{+} \\
=\mathrm{w}_{59}^{+}=1, \mathrm{w}_{55}^{-}=\mathrm{w}_{57}^{-} \\
=1.5) \\
\mathrm{P}_{2}\left(\mathrm{w}_{2}^{-}=1\right) \\
\mathrm{P}_{3}\left(\mathrm{w}^{+}{ }_{3}=\mathrm{w}_{4}^{+}=1\right) \\
\mathrm{P}_{4}\left(\mathrm{w}_{60}^{+}=1\right):\end{array}$ & $\begin{array}{l}X_{1}=80,000 \\
X_{2}=80,000 \\
X_{3}=80,000 \\
X_{4}=80,000 \\
X_{5}=10,000\end{array}$ & $\begin{array}{l}X_{6}=100,000 \\
X_{7}=100,000 \\
X_{8}=2,895 \\
X_{9}=2,500 \\
X_{10}=100,000\end{array}$ & $\begin{array}{l}X_{11}=1,000 \\
X_{12}=70,000 \\
X_{13}=2,000 \\
X_{14}=70,000 \\
X_{15}=57,000\end{array}$ & $\begin{array}{l}X_{16}=1,500 \\
X_{17}=1,000 \\
X_{18}=46,500 \\
X_{19}=1,000 \\
X_{20}=50,000\end{array}$ & $\begin{array}{l}X_{21}=1,500 \\
X_{22}=2,000 \\
X_{23}=50,000 \\
X_{24}=9,105 \\
X_{25}=2,000\end{array}$ & 156155.7 \\
\hline 3 & $\begin{array}{l}\mathrm{P}_{1}\left(\mathrm{w}_{1}^{+}=\mathrm{w}_{\mathrm{j}+4}^{-}=\mathrm{w}^{+}{ }_{\mathrm{j}+29}=\right. \\
\mathrm{w}^{+}{ }_{27}=\mathrm{w}_{55}^{-}=\mathrm{w}^{+}{ }_{56}=\mathrm{w}^{-} \\
\left.{ }_{57}=\mathrm{w}^{+}{ }_{58}=\mathrm{w}^{+}{ }_{59}=1\right) \\
\mathrm{P}_{2}\left(\mathrm{w}_{2}^{-}=2\right) \\
\mathrm{P}_{3}\left(\mathrm{w}^{+}=1.5, \mathrm{w}^{+}=1\right) \\
\mathrm{P}_{4}\left(\mathrm{w}_{60}^{+}=1.5\right)\end{array}$ & $\begin{array}{l}X_{1}=80,000 \\
X_{2}=50,000 \\
X_{3}=80,000 \\
X_{4}=80,000 \\
X_{5}=10,000\end{array}$ & $\begin{array}{l}X_{6}=100,000 \\
X_{7}=100,000 \\
X_{8}=87,500 \\
X_{9}=2,500 \\
X_{10}=100,000\end{array}$ & $\begin{array}{l}X_{11}=70,000 \\
X_{12}=70,000 \\
X_{13}=2,000 \\
X_{14}=1,000 \\
X_{15}=57,000\end{array}$ & $\begin{array}{l}X_{16}=1,500 \\
X_{17}=50,000 \\
X_{18}=45,000 \\
X_{19}=1,000 \\
X_{20}=2,500\end{array}$ & $\begin{array}{l}X_{21}=1,500 \\
X_{22}=2,000 \\
X_{23}=2,500 \\
X_{24}=2,000 \\
X_{25}=2,000\end{array}$ & 143941.0 \\
\hline 4 & $\begin{array}{l}\mathrm{P}_{1}\left(\mathrm{w}^{+}{ }_{1}=\mathrm{w}_{\mathrm{j}+4}^{-}=\mathrm{W}^{+}{ }_{\mathrm{j}+29=}\right. \\
\mathrm{w}^{+}{ }_{27}=\mathrm{w}^{-}{ }_{55}=\mathrm{w}^{+}{ }_{56}=\mathrm{w}^{-} \\
\left.{ }_{57}=\mathrm{w}^{+}{ }_{58}=\mathrm{w}^{+}{ }_{59}=1\right) \\
\mathrm{P}_{2}\left(\mathrm{w}_{2}{ }_{2}=1\right) \\
\mathrm{P}_{3}\left(\mathrm{w}^{+}=\mathrm{w}_{4}^{+}=.5\right) \\
\mathrm{P}_{4}\left(\mathrm{w}_{60}^{+}=1\right)\end{array}$ & $\begin{array}{l}X_{1}=59,000 \\
X_{2}=80,000 \\
X_{3}=80,000 \\
X_{4}=1,000 \\
X_{5}=10,000\end{array}$ & $\begin{array}{l}X_{6}=100,000 \\
X_{7}=100,000 \\
X_{8}=2,500 \\
X_{9}=2,500 \\
X_{10}=100,000\end{array}$ & $\begin{array}{l}X_{11}=55,000 \\
X_{12}=70,000 \\
X_{13}=2,000 \\
X_{14}=70,000 \\
X_{15}=3,000\end{array}$ & $\begin{array}{l}X_{16}=45,500 \\
X_{17}=1,000 \\
X_{18}=50,000 \\
X_{19}=1,000 \\
X_{20}=2,500\end{array}$ & $\begin{array}{l}X_{21}=50,000 \\
X_{22}=20,000 \\
X_{23}=2,500 \\
X_{24}=38,500 \\
X_{25}=2,000\end{array}$ & 154795.0 \\
\hline
\end{tabular}




\begin{tabular}{|c|c|c|c|c|c|c|c|}
\hline 5 & $\begin{array}{l}\mathrm{P}_{1}\left(\mathrm{w}_{1}^{+}=\mathrm{w}^{-}{ }_{\mathrm{j}+4}=\mathrm{w}^{+}{ }_{\mathrm{j}+29}=\right. \\
\mathrm{w}^{+}{ }_{27}=\mathrm{w}_{55}^{-}=\mathrm{w}^{+}{ }_{56}=\mathrm{w}_{57}^{-} \\
\left.=\mathrm{w}_{58}^{+}=\mathrm{w}_{59}^{+}=1\right) \\
\mathrm{P}_{2}\left(\mathrm{w}_{2}^{-}=.5\right) \\
\mathrm{P}_{3}\left(\mathrm{w}_{3}^{+}=\mathrm{w}_{4}^{+}=.5\right) \\
\mathrm{P}_{4}\left(\mathrm{w}_{60}^{+}=1\right)\end{array}$ & $\begin{array}{l}X_{1}=80,000 \\
X_{2}=50,000 \\
X_{3}=80,000 \\
X_{4}=80,000 \\
X_{5}=10,000\end{array}$ & $\begin{array}{l}X_{6}=100,000 \\
X_{7}=100,000 \\
X_{8}=87,500 \\
X_{9}=100,000 \\
X_{10}=100,000\end{array}$ & $\begin{array}{l}X_{11}=70,000 \\
X_{12}=70,000 \\
X_{13}=2,000 \\
X_{14}=1,000 \\
X_{15}=57,000\end{array}$ & $\begin{array}{l}X_{16}=1,500 \\
X_{17}=50,000 \\
X_{18}=45,000 \\
X_{19}=1,000 \\
X_{20}=2,500\end{array}$ & $\begin{array}{l}X_{21}=1,500 \\
X_{22}=2,000 \\
X_{23}=2,500 \\
X_{24}=2,000 \\
X_{25}=2,000\end{array}$ & 143941.0 \\
\hline 6 & $\begin{array}{l}\mathrm{P}_{1}\left(\mathrm{w}_{1}^{+}=\mathrm{w}_{\mathrm{j}+4}^{-}=\mathrm{w}^{+}{ }_{\mathrm{j}+29}=\right. \\
\mathrm{w}_{27}^{+}=\mathrm{w}_{56}^{+}=\mathrm{w}_{57}^{-}= \\
\left.\mathrm{w}_{58}^{+}=\mathrm{w}_{59}^{+}=1, \mathrm{w}_{55}^{-}=1.5\right) \\
\mathrm{P}_{2}\left(\mathrm{w}_{2}^{-}=1.5\right) \\
\mathrm{P}_{3}\left(\mathrm{w}_{3}^{+}{ }_{3}=\mathrm{w}_{4}^{+}=1\right) \\
\mathrm{P}_{4}\left(\mathrm{w}_{60}^{+}=.5\right)\end{array}$ & $\begin{array}{l}X_{1}=80,000 \\
X_{2}=80,000 \\
X_{3}=80,000 \\
X_{4}=80,000 \\
X_{5}=10,000\end{array}$ & $\begin{array}{l}X_{6}=100,000 \\
X_{7}=100,000 \\
X_{8}=2,500 \\
X_{9}=2,500 \\
X_{10}=100,000\end{array}$ & $\begin{array}{l}X_{11}=1,000 \\
X_{12}=70,000 \\
X_{13}=2,000 \\
X_{14}=70,000 \\
X_{15}=57,000\end{array}$ & $\begin{array}{l}X_{16}=1,500 \\
X_{17}=1,000 \\
X_{18}=46,500 \\
X_{19}=1,000 \\
X_{20}=50,000\end{array}$ & $\begin{array}{l}X_{21}=1,500 \\
X_{22}=2,000 \\
X_{23}=50,000 \\
X_{24}=9,500 \\
X_{25}=2,000\end{array}$ & 156296.2 \\
\hline
\end{tabular}

The solution of the problem indicates that all four goals in the given priority structure are fully achieved.

\section{CONCLUDING REMARKS}

This study demonstrates a LGP model to construct a mutual fund portfolio that allows incorporating multiple goals such as expected annual return, portfolio beta, standard deviation, and expense ratio. The results of the model indicate that the investor can achieve his fundamental objectives of constructing an efficient portfolio, meeting multiples investment goals. All feasible solutions have been considered using sensitivity analysis on the weight structures in the priority structure of the goals. The methodology applied in this paper is similar in approach to previous studies; however, it presents a different weight structure within a priority structure including additional goals and objectives. Additionally, the Euclidean distance function is used to measure distances of all possible solutions from the ideal solution. The model developed is flexible enough to accommodate other situation-specific constraints as may be defined by the goals and objectives of the problems. Performance of the model depends on the appropriate weights in a priority structure.

The model presented in this paper has been devised in a way that it may help the decision-maker find the proper weight structure within a priority structure to achieve desired goals, and may become a useful analytical tool for both financial advisors and investors.

Acknowledgements: The authors gratefully acknowledge Debasis Ghosh, David Shimberg and Marc Reid for their helpful comments and suggestions on the earlier draft of the paper.

\section{REFERENCES}

1. Charnes, A., Cooper, W. W. and Ferguson, R. O. (1955). Optimal Estimation of Executive Compensation by Linear Programming. Management Science, 1(2), 138-151.

2. Charnes, A and Cooper, W. W. (1961). Management Models and Industrial Applications of Linear Programming. Vol. I, John Wiley and Sons, New York.

3. Cohon, J. L. (1978). Multi-objective Programming and Planning. Academic Press, New York.

4. Cooper, W.W., Lelas, V. and Sueyoshi, T. (1997), Goal programming models and their duality relations for use in evaluating securitiy portfolio and regression relations, European Journal of Operational Research, 98 , 431-443.

5. Dominiak, C. (1997). An application of interactive multiple goal programming on the Warsaw Stock Exchange, in R. Caballero, F. Ruiz and R.E. Steuer (eds) Advances in Multiples Objective and Goal Programming, Springer, Berlin, 66-74.

6. Hwang, C. L. and Masud, A. S. M. (1979). Multiple Objective Decision Making: Methods and Applications. Springer-Verlag, Berlin.

7. Ignizio, J.P (1976). Goal Programming and Extensions. Lexington Books, Lexington, Massachusetts

8. Ijiri, Y. (1965). Management goals and accounting for control. North-Holland, Amsterdam.

9. Kumar, P. C., G. C. Philippatos, and J. R. Ezzell (1978). Goal Programming and Selection of 
10. Portfolio by Dual-Purpose Funds, Journal of Finance, 33(1), 303-310.

11. Kvanli, A.H. (1979). Financial planning using goal programming. Omega, 8(2), 207-218.

12. Lee, S.M. (1972). Goal programming for decision analysis. Auerbach, Philadelphia.

13. Lee, S.M. and Chesser, D.L. (1980). Goal programming for portfolio selection. Journal of Portfolio Management, 6, 22-26.

14. Lee, S.M. and Lerro, A.J. (1973). Optimizing the portfolio selection for mutual funds, Journal of Finance, 28, 1086-1101.

15. Leung, M.T., Daouk, H. and Chen, A. (2001). Using investment portfolio return to combine forecasts: a multiobjective approach, European Journal of Operational Research, 134, 84-102.

16. Levary, R.R. and Avery, M.L. (1984). On the practical application of weighting equities in a portfolio via goal programming. Opserach, 21, 246-261.

17. Markowitz, H.M. (1952), Portfolio selection, Journal of Finance, 12(1), 77-91.

18. Markowitz, H.M. (1959), Portfolio Selection, Wiley, New York..

19. Messac, A., Gupta, S. and Akbulut, B. (1996). Linear Physical Programming: A New Approach to Multiple Objective Optimization, Transactions on Operational Research, 8, 39-59.

20. Pendaraki, K., Doumpos, M. and Zopounidis, C. (2004), Towards a goal programming methodology for constructing equity mutual fund portfolios, Journal of Asset Management, 4(6), 415-428.

21. Romero, C. (1991). Handbook of critical issues in goal programming. Pergamon Press.

22. Romero, C. (1086). A survey of generalized goal programming (1970-1982). European Journal of Operational Research, 25, 188-191.

23. Schniederjans, M.J., et al. (1992). Allocating total wealth: A goal programming approach. Computers \& Operations Research, 20(7), 679-685.

24. Schniederjans, M.J. (1984). Linear goal programming. Petrocelli Books, Princeton, N.J.

25. Sharma, J.K., Sharma, Dinesh K. and Adeyeye, John O. (1995). Optimal portfolio selection: A goal programming approach. Indian Journal of Finance and Research, 7(2), 67-76.

26. Sharma, Dinesh K., Alade, J. A. and Vasishta (1999). Applications of Multiobjective Programming in MS/OR. Acta Ciencia Indica, XXV M(2), 225-228.

27. Sharma, Dinesh K., Ghosh, D. and Mattison, D. (2004). Finding economic order quantities with nonlinear goal programming. TOP - Spanish Statistical and Operations Research Society Journal, 12(2), 409-423.

28. Sharpe, W.F. (1963). A simplified model for portfolio analysis, Management Science, 9(1), 277-93.

29. Sharpe, W.F. (1967). A linear programming algorithm for mutual funds portfolio selection, Management Science, 13(3), 499-510.

30. Sharpe, W.F. (1971). A linear programming approximation for the general portfolio analysis problem, Journal of Financial and Quantitative Analysis, 6, 1263-75

31. Steuer, R.E. (1986). Multiple Criteria Optimization Theory, Computation and Application. Wiley, New York.

32. Steuer, R.E. (2003). Multiple criteria decision making combined with finance: A categorized bibliographic study. European Journal of Operational Research, 150, 496-515.

33. Stone, B.K. (1973). A linear programming formulation of the general portfolio selection problem, Journal of Financial and Quantitative Analysis, 8(4), 621-636.

34. Tamiz, M. and Jones, D.F.(1995). A Review of Goal Programming and its Applications. Annals of Operations Research, 58, 1995, 39-53. 